\title{
Staphylococcus aureus Infection Induced Oxidative Imbalance in Neutrophils: Possible Protective Role of Nanoconjugated Vancomycin
}

\author{
Subhankari Prasad Chakraborty, ${ }^{1}$ Panchanan Pramanik, ${ }^{2}$ and Somenath Roy \\ ${ }^{1}$ Immunology and Microbiology Laboratory, Department of Human Physiology with Community Health, Vidyasagar University, \\ West Bengal, Midnapore 721 102, India \\ ${ }^{2}$ Nanomaterials Laboratory, Department of Chemistry, Indian Institute of Technology, Midnapore, West Bengal, \\ Kharagpur 721 302, India
}

Correspondence should be addressed to Somenath Roy, roysomenath@hotmail.com

Received 6 November 2011; Accepted 19 December 2011

Academic Editors: M. Brunner and J. L. Cornish

Copyright (C) 2012 Subhankari Prasad Chakraborty et al. This is an open access article distributed under the Creative Commons Attribution License, which permits unrestricted use, distribution, and reproduction in any medium, provided the original work is properly cited.

\begin{abstract}
Staphylococcus aureus infection causes oxidative stress in neutrophils. The immune cells use reactive oxygen species (ROS) for carrying out their normal functions while an excess amount of ROS can attack cellular components that lead to cell damage. The present study was aimed to test the protective role of nanoconjugated vancomycin against vancomycin-sensitive Staphylococcus aureus (VSSA) and vancomycin-resistant Staphylococcus aureus (VRSA) infection induced oxidative stress in neutrophils. VSSA- and VRSA-infection were developed in Swiss mice by intraperitoneal injection of $5 \times 10^{6} \mathrm{CFU} / \mathrm{mL}$ bacterial solutions. Nanoconjugated vancomycin was treated to VSSA- and VRSA-infected mice at its effective dose for 10 days. Vancomycin was treated to VSSA and VRSA infected mice at similar dose, respectively, for 10 days. The result reveals that in vivo VSSA and VRSA infection significantly increases the level of lipid peroxidation, protein oxidation, oxidized glutathione level, and nitrite generation and decreases the level of reduced glutathione, antioxidant enzyme status, and glutathione-dependent enzymes as compared to control group; which were increased or decreased significantly near to normal in nanoconjugated vancomycin-treated group. These finding suggests the potential use and beneficial protective role of nanoconjugated vancomycin against VSSA and VRSA infection induced oxidative imbalance in neutrophils.
\end{abstract}

\section{Introduction}

Staphylococcus aureus is a major human pathogen causing large variety of infections worldwide with prevalence rate ranging from $4.6-54.4 \%$ [1-5]. S. aureus causes superficial skin infections to life-threatening diseases such as endocarditis, sepsis and soft tissue, urinary tract, respiratory tract, intestinal tract, and bloodstream infections $[6,7]$. The ability of $S$. aureus to survive in the eukaryotic intracellular environment could explain several aspects of chronic staphylococcal diseases and long-term colonization. Internalization may provide a mean of protection against host defenses and certain classes of antibiotics. Staphylococcal infections are typically associated with death of tissue, and evidence suggests intracellular bacteria are capable of inducing apoptosis.
S. aureus-mediated apoptosis has been reported in epithelial cells [8-10], keratinocytes [11], endothelial cells $[12,13]$, and osteoblasts [14]. Wesson et al. demonstrated host caspases8 and -3 to play a role in S. aureus-induced apoptosis, and caspase- 8 is known to be associated with apoptosis triggered by engagement of death receptors [10]. Resistance of $S$. aureus to antibiotics appeared within a few years after the onset of the antibiotic era [15], and this problem has reached epic proportions owing to overuse and improper use of anti-biotics [16]. S. aureus resistance to antibiotics currently spans all known classes of natural and synthetic compounds [17]. Increasing resistance of $S$. aureus to last line of drug, that is, vancomycin highlights the need for either the development of new and novel antibiotics $[18,19]$ or the improvement of efficacy of established antibiotics by the 
development of new agents capable of enhancing antibiotic activity [20].

Chitin, a natural biopolymer, is the major structural component of invertebrates like crab, shrimp, shells, and the cell walls of fungi. Chitosan (CS), the deacetylated form of chitin, is a linear polysaccharide, composed of glucosamine and $\mathrm{N}$-acetyl glucosamine linked in a $\beta$ linkage [21-24]. Carboxymethyl chitosan (CMC) is a linear polysaccharide composed of $\beta(1,4)$ glycosidic linkages between 6-carboxymethyl-D-glucosamine monomers. CMC is synthesized from CS by carboxylation of the hydroxyl and amine groups [25]. In our previous laboratory report, we synthesized CMC-EDBE-FA nanoparticle based on carboxy methyl chitosan tagged with folic acid by covalently linkage through 2,2' (ethylenedioxy)bis-(ethylamine), vancomycin was loaded onto it, complex is called "nanoconjugated vancomycin" and observe it's bactericidal activity against $S$. aureus [26]. In our recent laboratory report, we reported that CMC-EDBEFA nanoparticle is nontoxic [27]. We also reported that in vivo challenge of VSSA and VRSA for five days can produce the highest degree of damage in lymphocytes through the increased production of nitric oxide, TNF- $\alpha$ that leads to decreased antioxidant status in cell and ten days successive treatment of nanoconjugated vancomycin also eliminate in vivo VSSA and VRSA infection [28]. Recently, we reported that, nanoconjugated vancomycin can be used as a potent free-radical scavenger antioxidative product and can be used as a potential therapeutic agent against staphylococcal infection [29]. The present study was aimed to test the protective role of nanoconjugated vancomycin against VSSA and VRSA induced oxidative imbalance in neutrophils.

\section{Materials and Methods}

2.1. Chemicals and Reagents. Histopaque 1077, dextran, Sodium dodecyl sulfates (SDS), 2,4-dinitrophenyl hydrazine (DNPH), 5', 5'-dithio(bis)-2-nitrobenzoic acid (DTNB), standard reduced glutathione (GSH), glutathione reductase (GR), NADPH Na $\mathrm{Na}_{4} \mathrm{NADPH}$, oxidized glutathione (GSSG), agarose, folic acid (FA), Chitosan (medium molecular weight), dicyclohexyl carbodiimide (DCC), Trifluoroacetic acid, 2, 2' -(ethylenedioxy)-bis-(ethylamine) (EDBE), di-tertbutyldicarbonate $\left(\mathrm{BoC}_{2} \mathrm{O}\right), \mathrm{N}$-hydroxysuccinimide (NHS), and 1-[3-dimethylamino)propyl]-3-ethylcarbodiimide $\mathrm{Hy}$ drochloride (EDC) were purchased from Sigma Chemical Co., USA. Sodium chloride $(\mathrm{NaCl})$, sodium dodecyl sulfate, ethylene diamine tetra acetate (EDTA), tryptic soy broth, luria broth, mannitol salt agar, agar powder, sucrose, magnesium chloride $\left(\mathrm{MgCl}_{2}\right)$, and sodium azide $\left(\mathrm{NaN}_{3}\right)$ were purchased from Himedia, India. Tris-Hcl, Trisbuffer, potassium dihydrogen phosphate $\left(\mathrm{KH}_{2} \mathrm{PO}_{4}\right)$, dipotassium hydrogen phosphate $\left(\mathrm{K}_{2} \mathrm{HPO}_{4}\right)$, sodium hydroxide $(\mathrm{NaOH})$, sodium acetate, ammonium acetate, alcohol, sulfanilamide, phosphoric acid, and N-C-1 naphthyl ethylene diamine dihydrochloride and other chemicals were procured from Merck Ltd., SRL Pvt. Ltd., and Mumbai, India. All other chemicals were from Merck Ltd., SRL Pvt., Ltd., and Mumbai and were of the highest grade available.
2.2. Animals. Experiments were performed using Swiss male mice $6-8$ weeks old, weighing $20-25 \mathrm{~g}$. The animals were fed standard pellet diet and water were given ad libitum and housed in polypropylene cage (Tarson) in the departmental animal house with $12 \mathrm{~h}$ light: dark cycle and the temperature of $25 \pm 2^{\circ} \mathrm{C}$. The animals were allowed to acclimatize for one week. The animals used did not show any sign of malignancy or other pathological processes. Animals were maintained in accordance with the guidelines of the National Institute of Nutrition, Indian Council of Medical Research, Hyderabad, India and approved by the ethical committee of Vidyasagar University.

2.3. Bacterial Strain. We used coagulase positive vancomycin sensitive (MMC-6) and resistant (MMC-17) Staphylococcus aureus strains that were isolated from human post-operative pus sample [30]. These bacterial strains were grown at $37^{\circ} \mathrm{C}$ for overnight in tryptic soy broth. The bacterial culture was centrifuged at $15,000 \mathrm{rpm}$ for $15 \mathrm{~min}$. The pellet was resuspended and washed with sterile phosphate buffer saline (PBS). Using a UV-spectrophotometer (Schimadzu, USA) at an absorbance of $620 \mathrm{~nm}$, we adjusted the viable bacterial count to approximately $1.0 \times 10^{9}$ colony-forming units (CFU)/mL, which corresponded to an optical density of 1.6. The bacterial suspension was adjusted by serial dilution in phosphate buffer saline (PBS) to give a final concentration of approximately $5 \times 10^{6}$ in $100 \mu \mathrm{L}$ of bacterial suspension [31].

2.4. Development of VSSA and VRSA Infection in Swiss Mice. VSSA and VRSA infection was developed in male Swiss mice by intraperitoneal (i.p.) injection of $100 \mu \mathrm{L}$ of bacterial suspension containing $5 \times 10^{6} \mathrm{CFU} / \mathrm{mL}$ according to our previous laboratory report [28].

\subsection{Preparation of CMC-EDBE-FA Nanoparticle and Loading} of Vancomycin. CMC-EDBE-FA nanoparticle was prepared and vancomycin was loaded onto it according to our previous laboratory report [26].

2.6. Experimental Design. VSSA- and VRSA-infected mice were treated with nanoconjugated vancomycin for successive 10 days at a dose of $100 \mathrm{mg} / \mathrm{kg}$ bw/day and $500 \mathrm{mg} / \mathrm{kg}$ bw/day, respectively. The dose and duration of nanoconjugated vancomycin were selected from our previous laboratory report [28]. The following groups were considered for the experiment:

Group I: control;

Group II: VSSA-infected control;

Group III: VSSA infection $+100 \mathrm{mg} / \mathrm{kg}$ bw/day vancomycin;

Group IV: VSSA infection $+100 \mathrm{mg} / \mathrm{kg}$ bw/day nanoconjugated vancomycin;

Group V: VRSA-infected control;

Group VI: VRSA infection $+500 \mathrm{mg} / \mathrm{kg}$ bw/day vancomycin; 
Group VII: VRSA infection + $500 \mathrm{mg} / \mathrm{kg}$ bw/day nanoconjugated vancomycin.

After the termination of experiment, animals were sacrificed by an intraperitoneal injection of sodium pentobarbital (60$70 \mathrm{mg} / \mathrm{kg}$ body weight) [32] and blood ( $n=6 /$ group) was used for preparation neutrophils for biochemical estimation of different oxidative parameters.

2.7. Separation of Neutrophils. Heparinized blood samples were used for the separation of neutrophils. Blood samples were diluted with equal amount of PBS ( $\mathrm{pH}$ 7.0) buffer and then layered very carefully on the density gradient (Histopaque 1077, Sigma Chemical Co.) in 1:2 ratio. Centrifuged at $500 \mathrm{~g}$ for $20 \mathrm{~min}$ and the white milky layer of mononuclear cells that is lymphocytes was carefully removed. Neutrophils were isolated from buffy coat with RBC layer followed by dextran sedimentation and hypotonic lysis to remove red blood cells. The pellets of neutrophil were lysed in a hypotonic lysis buffer for $45 \mathrm{~min}$ at $37^{\circ} \mathrm{C}$ and kept at $-86^{\circ} \mathrm{C}$ until biochemical estimations of different parameters [33].

\subsection{Biochemical Estimation}

2.8.1. Nitrite (NO) Production by Neutrophils. NO generation in cell lysate was assessed according to Sanai et al. 1998, with slight modification [34]. Sodium nitroprusside $(100 \mathrm{mM})$, in phosphate-buffered saline, was mixed with $200 \mu \mathrm{L}$ sample and incubated at room temperature for $150 \mathrm{~min}$. After that, Griess reagent $(0.5 \mathrm{~mL})$ (Containing $1 \%$ sulfanilamide in 5\% phosphoric acid and $0.1 \% \mathrm{~N}-\mathrm{C}-1$ naphthyl ethylene diamine dihydrochloride in $1: 1$ ratio) was added and incubated at room temperature for $10 \mathrm{~min}$. The absorbance of the chromophore formed was read at $550 \mathrm{~nm}$ with a double beam Hitachi U2001 UV/Visible spectrophotometer (USA). NO generation was calculated using the sodium nitrite standard curve and expressed as $\mu \mathrm{mol} / \mathrm{mg}$ protein.

2.8.2. Determination of Lipid Peroxidation (MDA) in Neutrophils. Lipid peroxidation was estimated by the method of Ohkawa et al. in cell lysate [35]. Briefly, the reaction mixture contained Tris- $\mathrm{HCl}$ buffer ( $50 \mathrm{mM}, \mathrm{pH} 7.4)$, tertbutyl hydroperoxide (BHP) $\left(500 \mu \mathrm{M}\right.$ in ethanol) and $1 \mathrm{mM} \mathrm{FeSO}_{4}$. After incubating the samples at $37^{\circ} \mathrm{C}$ for $90 \mathrm{~min}$, the reaction was stopped by adding $0.2 \mathrm{~mL}$ of $8 \%$ sodium dodecyl sulfate (SDS) followed by $1.5 \mathrm{~mL}$ of $20 \%$ acetic acid ( $\mathrm{pH} 3.5$ ). The amount of malondialdehyde (MDA) formed during incubation was estimated by adding $1.5 \mathrm{~mL}$ of $0.8 \%$ TBA and further heating the mixture at $95^{\circ} \mathrm{C}$ for $45 \mathrm{~min}$. After cooling, samples were centrifuged, and the TBA reactive substances (TBARS) were measured in supernatants at $532 \mathrm{~nm}$ by using $1.53 \times 10^{5} \mathrm{M}^{-1} \mathrm{~cm}^{-1}$ as extinction coefficient. The levels of lipid peroxidation were expressed in terms of $n \mathrm{~mol} / \mathrm{mg}$ protein.

2.8.3. Protein Carbonyls (PC) Contents in Neutrophils. Protein oxidation was monitored by measuring protein carbonyl contents by derivatization with 2,4-dinitrophenyl hydrazine
(DNPH) [36]. In general, cell lysate proteins in $50 \mathrm{mM}$ potassium phosphate buffer, $\mathrm{pH}$ 7.4, were derivatized with DNPH $(21 \%$ in $2 \mathrm{~N} \mathrm{HCl})$. Blank samples were mixed with $2 \mathrm{~N} \mathrm{HCl}$ incubated at $1 \mathrm{~h}$ in the dark; protein was precipitated with $20 \%$ trichloro acetic acid (TCA). Underivatized proteins were washed with an ethanol: ethyl acetate mixture $(1: 1)$. Final pellets of protein were dissolved in $6.0 \mathrm{~N}$ guanidine hydrochloride and absorbance was measured at $370 \mathrm{~nm}$. Protein carbonyls content was expressed in terms of $n \mathrm{~mol} / \mathrm{mg}$ protein.

2.8.4. Determination of Reduced Glutathione (GSH) Level in Neutrophils. Reduced glutathione estimation in the cell lysate was performed by the method of Moron et al. 1979 [37]. The required amount of the cell lysate was mixed with $25 \%$ of trichloroacetic acid and centrifuged at 2,000 $\mathrm{g}$ for $15 \mathrm{~min}$ to settle the precipitated proteins. The supernatant was aspirated and diluted to $1 \mathrm{~mL}$ with $0.2 \mathrm{M}$ sodium phosphate buffer ( $\mathrm{pH} 8.0$ ). Later, $2 \mathrm{~mL}$ of $0.6 \mathrm{mM}$ DTNB was added. After $10 \mathrm{~min}$ the optical density of the yellow-colored complex formed by the reaction of GSH and DTNB (Ellman's reagent) was measured at $405 \mathrm{~nm}$. A standard curve was obtained with standard reduced glutathione. The levels of GSH were expressed as $\mu \mathrm{g}$ of GSH/mg protein.

2.8.5. Determination of Oxidized Glutathione (GSSG) Level in Neutrophils. The oxidized glutathione level was measured after derivatization of GSH with 2-vinylpyidine according to the method of Griffith, 1980 [38]. In brief, with $0.5 \mathrm{~mL}$ cell lysate, $2 \mu \mathrm{L}$ 2-vinylpyidine was added and incubated for $1 \mathrm{hr}$ at $37^{\circ} \mathrm{C}$. Then the mixture was deprotienized with $4 \%$ sulfosalicylic acid and centrifuged at 1,000 g for $10 \mathrm{~min}$ to settle the precipitated proteins. The supernatant was aspirated and GSSG level was estimated with the reaction of DTNB at $412 \mathrm{~nm}$ in spectrophotometer and calculated with standard GSSG curve. The levels of GSSG were expressed as $\mu \mathrm{g}$ of GSSG/mg protein.

2.8.6. Activity of Super Oxide Dismutase (SOD) in Neutrophils. SOD activity was determined from its ability to inhibit the autooxidation of pyrogallol according to Mestro Del and McDonald, 1986 [39]. The reaction mixture considered is of $50 \mathrm{mM}$ Tris (hydroxymethyl) aminomethane ( $\mathrm{pH} 8.2$ ), $1 \mathrm{mM}$ diethylenetriamine penta acetic acid, and $20-50 \mu \mathrm{L}$ of cell lysate. The reaction was initiated by addition of $0.2 \mathrm{mM}$ pyrogallol, and the absorbance is measured kinetically at $420 \mathrm{~nm}$ at $25^{\circ} \mathrm{C}$ for $3 \mathrm{~min}$. SOD activity was expressed as unit/mg protein.

2.8.7. Activity of Catalase (CAT) in Neutrophils. Catalase activity was measured in the cell lysate by the method of Luck, 1963 [40]. The final reaction volume of $3 \mathrm{~mL}$ contained $0.05 \mathrm{M}$ tris-buffer, $5 \mathrm{mM}$ EDTA ( $\mathrm{pH} 7.0$ ) and $10 \mathrm{mM} \mathrm{H}_{2} \mathrm{O}_{2}$ (in $0.1 \mathrm{M}$ potassium phosphate buffer, $\mathrm{pH} 7.0$ ). About $50 \mu \mathrm{L}$ aliquot of the cell lysates was added to the above mixture. The rate of change of absorbance per min at $240 \mathrm{~nm}$ was recorded. Catalase activity was calculated by using the molar 
extinction coefficient of $43.6 \mathrm{M}^{-1} \mathrm{~cm}^{-1}$ for $\mathrm{H}_{2} \mathrm{O}_{2}$. CAT activity was expressed as unit/mg protein.

2.8.8. Activity of Glutathione Peroxidase (GPx) in Neutrophils. The GPx activity was measured by the method of Paglia and Valentine, 1967 [41]. The reaction mixture contained $50 \mathrm{mM}$ potassium phosphate buffer ( $\mathrm{pH}$ 7.0), $1 \mathrm{mM}$ EDTA, $1 \mathrm{mM}$ sodium azide, $0.2 \mathrm{mM} \mathrm{NADPH}, 1 \mathrm{U}$ glutathione reductase, and $1 \mathrm{mM}$ reduced glutathione. The sample, after its addition, was allowed to equilibrate for $5 \mathrm{~min}$ at $25^{\circ} \mathrm{C}$. The reaction was initiated by adding $0.1 \mathrm{~mL}$ of $2.5 \mathrm{mM} \mathrm{H}_{2} \mathrm{O}_{2}$. Absorbance at $340 \mathrm{~nm}$ was recorded for $5 \mathrm{~min}$. Values were expressed as $n \mathrm{~mol}$ of NADPH oxidized to NADP by using the extinction coefficient of $6.2 \times 103 \mathrm{M}^{-1} \mathrm{~cm}^{-1}$ at $340 \mathrm{~nm}$. The activity of GPx was expressed in terms of $n$ mol NADPH consumed $/ \mathrm{min} / \mathrm{mg}$ protein.

2.8.9. Activity of Glutathione Reductase (GR) in Neutrophils. The GR activity was measured by the method of Miwa, 1972 [42]. The tubes for enzyme assay were incubated at $37^{\circ} \mathrm{C}$ and contained $2.0 \mathrm{~mL}$ of $9 \mathrm{mM}$ GSSG, $0.02 \mathrm{~mL}$ of $12 \mathrm{mM}$ $\mathrm{NADPH}, \mathrm{Na}_{4}, 2.68 \mathrm{~mL}$ of $1 / 15 \mathrm{M}$ phosphate buffer ( $\mathrm{pH} 6.6$ ), and $0.1 \mathrm{~mL}$ of cell lysate. The activity of this enzyme was determined by monitoring the decrease in absorbance at $340 \mathrm{~nm}$. The activity of GR was expressed in terms of $n$ mol $\mathrm{NADPH}$ consumed/min/mg protein.

2.8.10. Activity of Glutathione-s-Transferase (GST) in Neutrophils. The activity of GST activity was measured by the method of Habig et al. 1974 [43]. The tubes of enzyme assay were incubated at $25^{\circ} \mathrm{C}$ and contained $2.85 \mathrm{~mL}$ of $0.1 \mathrm{M}$ potassium phosphate $(\mathrm{pH}$ 6.5) containing $1 \mathrm{mM}$ of GSH, $0.05 \mathrm{~mL}$ of $60 \mathrm{mM}$ 1-chloro-2,4-dinitrobengene, and $0.1 \mathrm{~mL}$ cell lysate. The activity of this enzyme was determined by monitoring the increase in absorbance at $340 \mathrm{~nm}$. The activity of GST was expressed in terms of $n$ mol NADPH consumed $/ \mathrm{min} / \mathrm{mg}$ protein.

2.8.11. Protein Estimation. Protein was determined using bovine serum albumin as standard according to Lowry et al. 1951 [44].

2.9. Statistical Analysis. The experiments were performed three times and the data are presented as mean \pm S.E.M. Comparisons of the means of control and experimental groups were made by two-way ANOVA test (using a statistical package, Origin 6.1, Northampton, MA 01060, USA) with multiple comparison $t$-tests, $P<0.05$ as a limit of significance.

\section{Results}

3.1. Nitrate (NO) Generation. Nitrite generation (NO) that occurred by inducible nitric oxide synthase (iNOS) can then combine with superoxide and be able to generate a product which has much more toxicity such as peroxynitrite $\left(\mathrm{ONOO}^{-}\right)$. NO generation was significantly $(P<0.05)$ increased in VSSA- and VRSA-infected neutrophils by $135.45 \%$ and $145.32 \%$, respectively in compare with control, which was also significantly $(P<0.05)$ decreased in nanoconjugated vancomycin-treated group by $46.30 \%$ and $49.44 \%$. It was observed from our study that treatment of vancomycin significantly $(P<0.05)$ decreased the NO generation by $32.68 \%$ in VSSA infection, whereas 5.64\% in VRSA infection, which was not significant (Figure 1).

3.2. Lipid Peroxidation Level. Lipid peroxidation is an important determinant to access the cellular damage. Lipid peroxidation in terms of malondialdehyde level was significantly $(P<0.05)$ increased in neutrophils by $145.28 \%$ and $186.48 \%$, respectively, due to VSSA and VRSA infection as compared to control group, which was significantly $(P<$ 0.05 ) decreased by $44.52 \%$ and $45.37 \%$, respectively, due to treatment of nanoconjugated vancomycin. Treatment of vancomycin decreased MDA levels significantly $(P<0.05)$ in VSSA-infected neutrophils by $34.39 \%$, whereas $4.59 \%$ in VRSA-infected neutrophils which was not significant (Figure 2).

3.3. Protein Oxidation Level. Protein oxidation in terms of protein carbonyls (PC) is an important determination of cellular injury. Protein carbonyl level was significantly $(P<$ 0.05 ) increased in neutrophils by $140.38 \%$ and $187.44 \%$, respectively, due to VSSA and VRSA infection as compared to control group, which was significantly $(P<0.05)$ decreased by $45.19 \%$ and $46.94 \%$, respectively, due to treatment of nanoconjugated vancomycin. Treatment of vancomycin decreased PC levels significantly $(P<0.05)$ in VSSA-infected neutrophils by $33.81 \%$, whereas $10.89 \%$ in VRSA-infected neutrophils which was not significant (Figure 2).

3.4. Reduced and Oxidized Glutathione Level. Glutathione is an important antioxidant in cellular system. So, to understand glutathione level, we have measured both reduced and oxidized form of glutathione. Reduced glutathione level was significantly $(P<0.05)$ diminished in neutrophils by $67.50 \%$ and $53.04 \%$, respectively, due to VSSA and VRSA infection as compared to control group, which was significantly $(P<$ 0.05 ) increased by $161.62 \%$ and $91.98 \%$ due to treatment of nanoconjugated vancomycin. Treatment of vancomycin increased reduced glutathione level significantly $(P<$ 0.05 ) in VSSA-infected neutrophils by $128.14 \%$, whereas $3.84 \%$ in VRSA-infected neutrophils which is not significant (Figure 3). Oxidized glutathione level was significantly $(P<$ 0.05 ) elevated in neutrophils by $90.11 \%$ and $103.64 \%$, respectively, due to VSSA and VRSA infection as compared to control group, which was significantly $(P<0.05)$ decreased by $40.64 \%$ and $38.43 \%$ due to treatment of nanoconjugated vancomycin. Treatment of vancomycin decreased oxidized glutathione level significantly $(P<0.05)$ in VSSA-infected neutrophils by $23.01 \%$, whereas $5.15 \%$ in VRSA-infected neutrophils which was not significant (Figure 3).

3.5. Superoxide Dismutase (SOD) Activity. Superoxide dismutase catalyzes the breakdown of superoxide radical into 


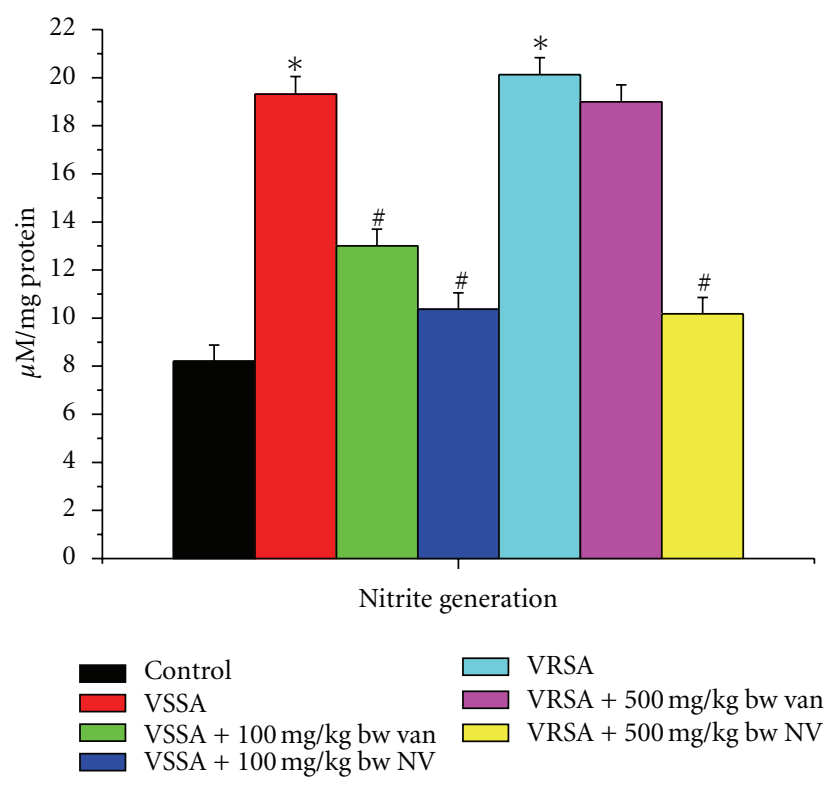

FIGURE 1: Nitrite generation (NO) in control, VSSA infection control, VSSA infection $+100 \mathrm{mg} / \mathrm{kg}$ bw/day vancomycin, VSSA infection + $100 \mathrm{mg} / \mathrm{kg}$ bw/day nanoconjugated vancomycin, VRSA infection control, VRSA infection $+500 \mathrm{mg} / \mathrm{kg}$ bw/day vancomycin, and VRSA infection $+500 \mathrm{mg} / \mathrm{kg}$ bw/day nanoconjugated vancomycin for 10 days treated neutrophils. Values are expressed as mean $\pm \mathrm{SEM}, n=6$. *Indicates significant difference $(P<0.05)$ compared to control group. ${ }^{*}$ Indicates significant difference $(P<0.05)$ compared to infection control group.

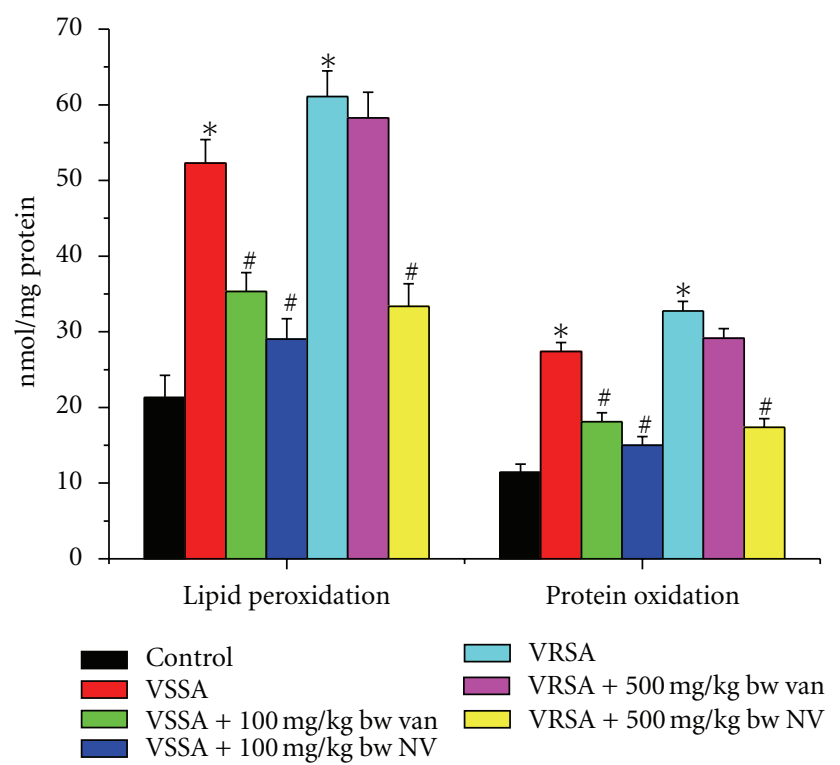

FIGURE 2: Lipid peroxidation (MDA) and protein oxidation (PC) level in control, VSSA infection control, VSSA infection $+100 \mathrm{mg} /$ $\mathrm{kg}$ bw/day vancomycin, VSSA infection $+100 \mathrm{mg} / \mathrm{kg}$ bw/day nanoconjugated vancomycin, VRSA infection control, VRSA infection + $500 \mathrm{mg} / \mathrm{kg}$ bw/day vancomycin, and VRSA infection $+500 \mathrm{mg} / \mathrm{kg}$ bw/day nanoconjugated vancomycin for 10 days treated neutrophils. Values are expressed as mean \pm SEM, $n=6$. ${ }^{*}$ Indicates significant difference $(P<0.05)$ compared to control group. "Indicates significant difference $(P<0.05)$ compared to infection control group.

oxygen and hydrogen peroxide. SOD activity was significantly $(P<0.05)$ diminished in neutrophils by $44.03 \%$, and $35.31 \%$, respectively, due to VSSA and VRSA infection as compared to control group, which was significantly $(P<0.05)$ increased by $67.16 \%$ and $40.09 \%$ due to treat- ment of nanoconjugated vancomycin. Treatment of vancomycin increased SOD activity significantly $(P<0.05)$ in VSSA-infected neutrophils by $39.24 \%$, whereas $11.25 \%$ in VRSA-infected neutrophils which was not significant (Figure 4). 


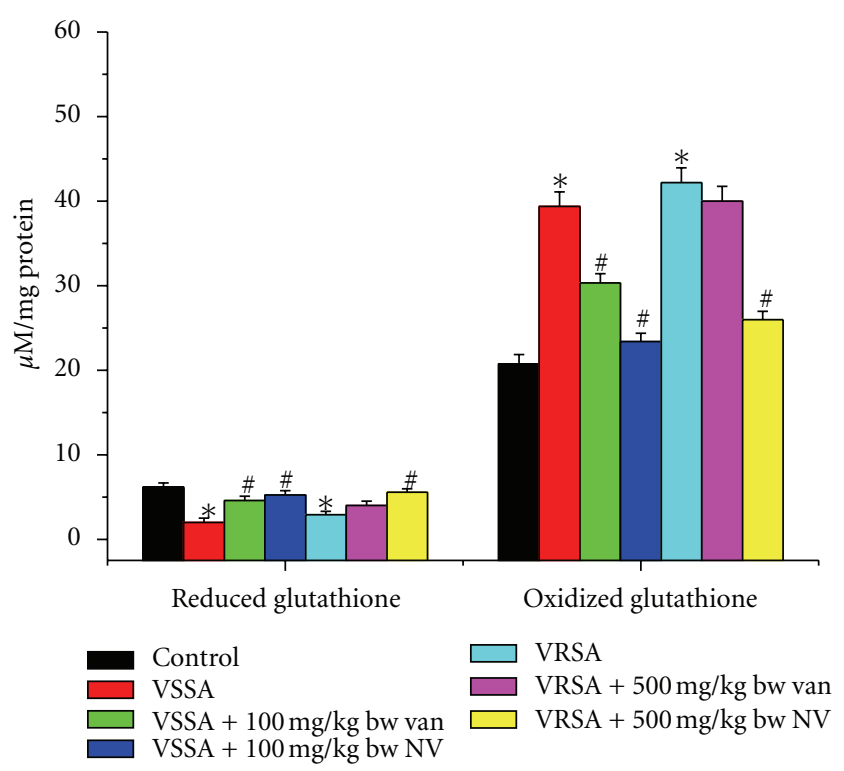

FIGURE 3: Reduced glutathione (GSH) and oxidized glutathione (GSSG) level in control, VSSA infection control, VSSA infection + $100 \mathrm{mg} / \mathrm{kg}$ bw/day vancomycin, VSSA infection $+100 \mathrm{mg} / \mathrm{kg}$ bw/day nanoconjugated vancomycin, VRSA infection control, VRSA infection + $500 \mathrm{mg} / \mathrm{kg}$ bw/day vancomycin, and VRSA infection $+500 \mathrm{mg} / \mathrm{kg}$ bw/day nanoconjugated vancomycin for 10 days treated neutrophils. Values are expressed as mean \pm SEM, $n=6 .{ }^{*}$ Indicates significant difference $(P<0.05)$ compared to control group. ${ }^{*}$ Indicates significant difference $(P<0.05)$ compared to infection control group.

3.6. Catalase (CAT) Activity. Catalase catalyzes the conversion of hydrogen peroxide to oxygen and water. CAT activity was significantly $(P<0.05)$ decreased in neutrophils by $61.40 \%$ and $56.47 \%$, respectively, due to VSSA and VRSA infection as compared to control group, which was significantly $(P<0.05)$ increased by $99.44 \%$ and $123.04 \%$ due to treatment of nanoconjugated vancomycin. Treatment of vancomycin increased CAT activity significantly $(P<0.05)$ in VSSA-infected neutrophils by $24.99 \%$, whereas $1.36 \%$ in VRSA-infected neutrophils which was not significant (Figure 4).

3.7. Glutathione Peroxidase (GPx) Activity. The glutathione peroxidase (GPx) activity was measured to understand the antioxidant enzyme status of different experimental group of neutrophils. GPx activity was significantly $(P<0.05)$ diminished in neutrophils by $74.17 \%$ and $75.70 \%$, respectively, due to VSSA and VRSA infection as compared to control group, which was significantly $(P<0.05)$ increased by $217.13 \%$ and $248.95 \%$ due to treatment of nanoconjugated vancomycin. Treatment of vancomycin increased GPx activity significantly $(P<0.05)$ in VSSA-infected neutrophils by $155.94 \%$, whereas $8.42 \%$ in VRSA-infected neutrophils which was not significant (Figure 5).

3.8. Glutathione Reductase (GR) Activity. The glutathione reductase (GR) activity was measured to understand the antioxidant enzyme status of different experimental group of neutrophils. GR activity was significantly $(P<0.05)$ decreased in neutrophils by $56.17 \%$ and $57.19 \%$, respectively, due to VSSA and VRSA infection as compared to control group, which was significantly $(P<0.05)$ increased by
$104.65 \%$ and $111.96 \%$ due to treatment of nanoconjugated vancomycin. Treatment of vancomycin increased GR activity significantly $(P<0.05)$ in VSSA-infected neutrophils by $58.64 \%$, whereas $4.74 \%$ in VRSA-infected neutrophils which was not significant (Figure 5).

3.9. Glutathione-s-Transferase (GST) Activity. The glutathione-s-transferase (GST) activity was measured to understand the antioxidant enzyme status of different experimental group of neutrophils. GST activity was significantly $(P<$ 0.05 ) diminished in neutrophils by $50.13 \%$ and $50.62 \%$, respectively, due to VSSA and VRSA infection as compared to control group, which was significantly $(P<0.05)$ increased by $73.62 \%$ and $78.38 \%$ due to treatment of nanoconjugated vancomycin. Treatment of vancomycin increased GST activity significantly $(P<0.05)$ in VSSA-infected neutrophils by $48.0 \%$, whereas $6.35 \%$ in VRSA-infected neutrophils which was not significant (Figure 5).

\section{Discussion}

Nature has provided cells with very strong biological antioxidant defense mechanisms. These include a variety of enzymatic and nonenzymatic molecules with enormous capabilities to mitigate the deleterious and potentially harmful effects of ROS and other free radicals. One of the primary antioxidant defense mechanisms is the GSH redox system. The enzymes of this system provide a formidable protective shield against oxidative damage. Alterations in their activities ultimately may result in irreversible manifestation of cellular damage [45]. In this context, our present study proves to be more relevant and will help further study in investigating the 


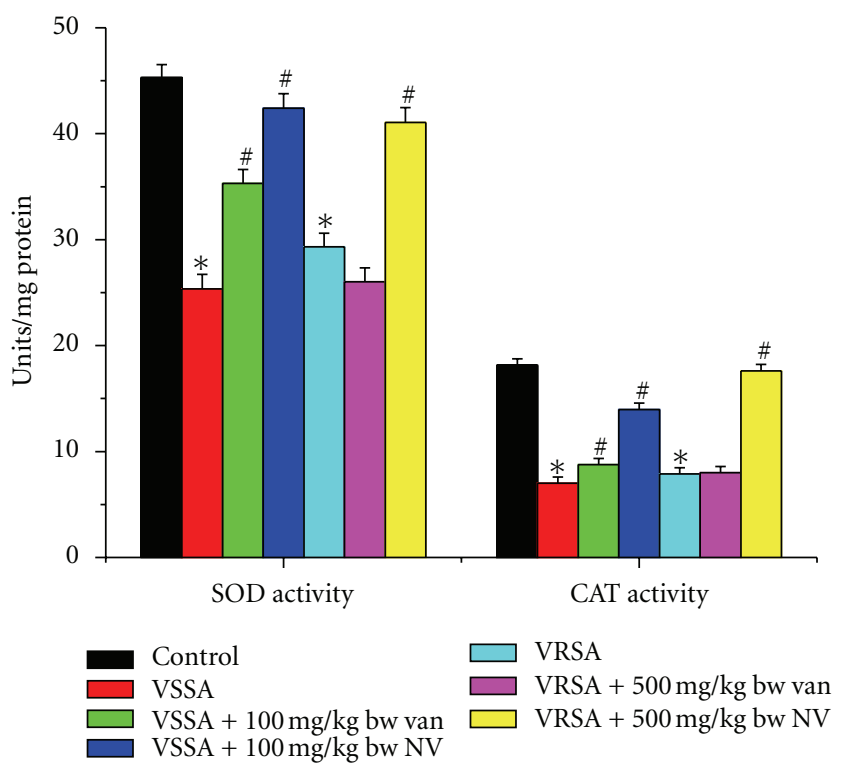

Figure 4: Activity of superoxide dismutase (SOD) and Catalase (CAT) in control, VSSA infection control, VSSA infection + 100 mg/ $\mathrm{kg}$ bw/day vancomycin, VSSA infection $+100 \mathrm{mg} / \mathrm{kg}$ bw/day nanoconjugated vancomycin, VRSA infection control, VRSA infection + $500 \mathrm{mg} / \mathrm{kg}$ bw/day vancomycin, and VRSA infection $+500 \mathrm{mg} / \mathrm{kg}$ bw/day nanoconjugated vancomycin for 10 days treated neutrophils. Values are expressed as mean \pm SEM, $n=6 .{ }^{*}$ Indicates significant difference $(P<0.05)$ compared to control group. ${ }^{*}$ Indicates significant difference $(P<0.05)$ compared to infection control group.

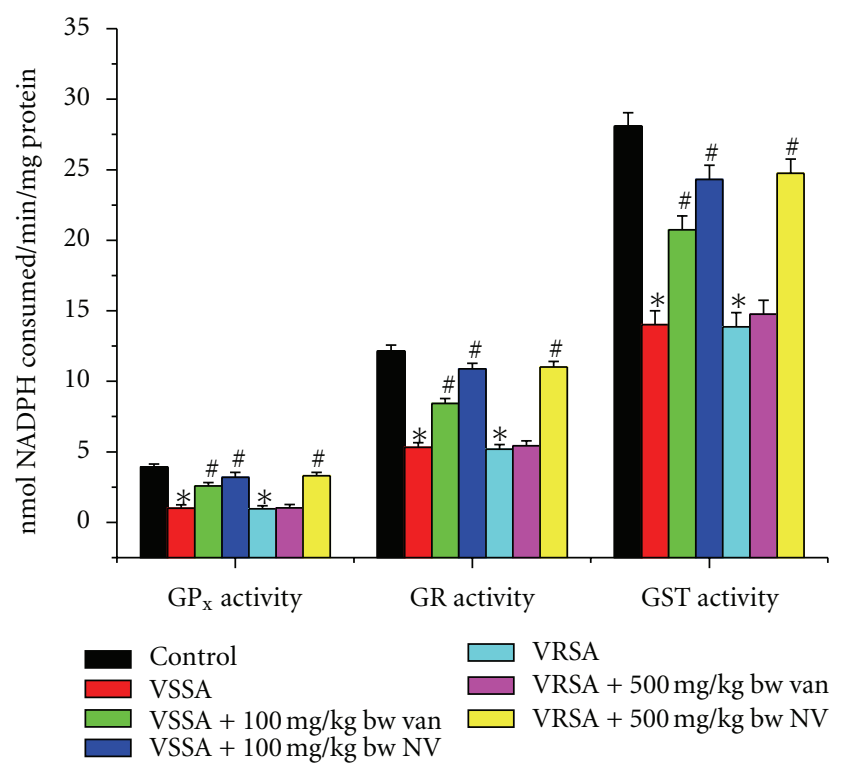

FIGURE 5: Activity glutathione peroxidase $\left(\mathrm{GP}_{\mathrm{x}}\right)$, glutathione reductase (GR) and glutathione-s-transferase (GST) in control, VSSA infection control, VSSA infection $+100 \mathrm{mg} / \mathrm{kg}$ bw/day vancomycin, VSSA infection $+100 \mathrm{mg} / \mathrm{kg}$ bw/day nanoconjugated vancomycin, VRSA infection control, VRSA infection $+500 \mathrm{mg} / \mathrm{kg}$ bw/day vancomycin, and VRSA infection $+500 \mathrm{mg} / \mathrm{kg}$ bw/day nanoconjugated vancomycin for 10 days treated neutrophils. Values are expressed as mean \pm SEM, $n=6$. ${ }^{*}$ Indicates significant difference $(P<0.05)$ compared to control group. \#Indicates significant difference $(P<0.05)$ compared to infection control group.

protective role of nanoconjugated vancomycin against VSSAand VRSA-induced oxidative stress in neutrophils.

CMC-EDBE-FA nanoparticle was prepared by the carboxylic group $(-\mathrm{COOH})$ of folic acid and $-\mathrm{COOH}$ group of functionalized carboxymethyl chitosan connected through the end-amino groups hydrophilic spacer, 2,2'-(ethylenedi- oxy)-bis-ethylamine. It is well known that carboxymethyl chitosan is easily soluble in water but folic acid is very less solubility in water. When carboxymethyl chitosan is connected by folic acid through a spacer, carboxymethyl chitosan may act as a hydrophilic part and folic acid as a hydrophobic part. It is evident from our study that, in vivo VSSA and VRSA 
infection in neutrophils of mice is associated with enhanced nitrate generation, MDA level, PC level, GSSG level, and decreased GSH level and as well as decreased enzymatic antioxidant (SOD, CAT, GPx, GR, and GST) activity, which are ameliorated by treatment of nanoconjugated vancomycin (Figures 1-5).

In this study, significant elevation of nitrate generation in neutrophils was observed in VSSA- and VRSA-infected mice. Treatment of nanoconjugated vancomycin to VSSA- and VRSA-infected mice decreased the NO generation (Figure 1). Nitric oxide (NO) is a free radical synthesized by nitric oxide synthase (NOS). NOS is composed of two identical monomers with molecular weights ranging from 130 to $160 \mathrm{kDa}$ [46]. Our previous study shown that nitric oxide synthesis in lymphocytes and as well as release in serum is high during VSSA and VRSA infection, which can be related to an alteration in oxidant-antioxidant potential [28]. Thus, higher level of nitrite generation by VSSA and VRSA infection may be due to high production of ROS. Nanoconjugated vancomycin plays the role of antioxidant to prevent the nitrate generation may be through the inhibition of inducible nitric oxide synthase (iNOS) expression [47]. Thus, in addition to the cellular antioxidant system, nanoconjugated vancomycin may indirectly protect neutrophils from VSSA and VRSA infection induced cellular changes. Thus, free radical depletion by the antioxidant agents seems to be beneficial for preventing the damage of lipid and protein.

In this study, significant elevation of malondialdehyde (MDA) and protein carbonyl level was observed in neutrophils of VSSA- and VRSA-infected mice. Treatment of nanoconjugated vancomycin to VSSA- and VRSA-infected mice decreased lipid peroxidation and protein oxidation significantly in neutrophils (Figure 2). It may be due to the generation of free radicals (mainly NO) which may react with protein in addition to lipids. Lipid peroxidation is known to disturb the integrity of cellular membranes leading to the leakage of cytoplasmic enzymes [48]. Protein carbonyls formation has been indicated to be an earlier marker of protein oxidation. Oxidation of protein may be due to either excessive oxidation of proteins or decreased capacity to cleanup oxidative damaged proteins. Oxidative modification of proteins may lead to the structural alteration and functional inactivation of many enzyme proteins [49], as evidenced by the decreased activity of different antioxidant enzymes like SOD, CAT, GPx, GR, and GST.

Reactive oxygen species (ROS) are generated during oxidative metabolism and can inflict damage on all classes of cellular macromolecules and eventually leading to cell death. An elevation in free radical formation can be accompanied by an immediate compensatory increase in the activities of the free radical scavenging enzymes [50]. Imbalance between the generation of reactive oxygen species (ROS) and the antioxidant system causes oxidative stress. Glutathione, an important cellular reductant, is involved in protection against free radicals, peroxides, and toxic compounds in cellular systems [51]. In the present study, the reduced glutathione level was significantly decreased in neutrophils of VSSA- and VRSAinfected mice. Treatment of nanoconjugated vancomycin to VSSA- and VRSA-infected mice increased the GSH level
(Figure 3). In this study, it was observed that oxidized glutathione level was increased in VSSA- and VRSA-infected neutrophils, which was ameliorated due to nanoconjugated vancomycin treatment (Figure 3). The decreased GSH levels represent its increased utilization due to VSSA and VRSA infection. On the other hand, decreasing GSH level may be due to increasing level of lipid oxidation products which may be associated with less availability of NADPH required for the activity of glutathione reductase (GR) to transform GSSG to GSH [52] due to the increasing production of ROS in form of NO. In our present study, the increasing levels of GSSG and decreasing GR activity (Figure 5) due to VSSA and VRSA infection may support the explanation.

Antioxidant enzymes are considered to be a primary defense that prevents biological macromolecules from oxidative damage. SOD rapidly dismutates superoxide anion $\left(\mathrm{O}_{2}{ }^{\bullet-}\right)$ to less dangerous $\mathrm{H}_{2} \mathrm{O}_{2}$, which is further degraded by CAT and GPx to water and oxygen [53]. The results of the present study showed a significant fall in SOD and CAT activities in neutrophils of VSSA- and VRSA-infected group. Treatment of nanoconjugated vancomycin to VSSAand VRSA-infected mice significantly increased the SOD and CAT activity in neutrophils (Figure 4). SOD, dismutate $\mathrm{O}_{2}{ }^{--}$ and the same in turn is a potent inhibitor of CAT [54]. The depletion in SOD activity may be due to dispose off the free radicals, produced due to VSSA and VRSA infection. Beside this, during infection, $\mathrm{H}_{2} \mathrm{O}_{2}$ produced by dismutation of superoxide anion may have been efficiently converted to $\mathrm{O}_{2}$ by CAT and the enzyme activities showed a marked reduction. The depletion of antioxidant enzyme activity may be due to inactivation of the enzyme proteins by VSSA and VRSA infection induced NO generation, depletion of the enzyme substrates, and/or downregulation of transcription and translation processes.

GPx works nonspecifically to scavenge and decompose excess hydroperoxides including $\mathrm{H}_{2} \mathrm{O}_{2}$, which may be prevalent under oxidative stress [55-57]. Glutathione-s-transferase (GST) mainly detoxifies electrophilic compounds [58] and has a well-established role in protecting cells from mutagens and carcinogens as a free-radical scavenger along with glutathione. In the present study, the significant decreasing of GSH level and GSH-dependent enzymes, that is, GPx, GR, and GST (Figure 5) in neutrophils of VSSA and VRSA infection may be due to increased utilization to scavenge the free-radical generation. Treatment of nanoconjugated vancomycin to VSSA- and VRSA-infected mice significantly increased the GPx, GR, and GST activity in neutrophils (Figure 5).

In conclusion, the study described here, neutrophils are susceptible to $S$. aureus infection through the increased production of nitric oxide which leads to decreased antioxidant status in cell and nanoconjugated vancomycin protects the neutrophils from such infection by decreasing NO generation, lipid, and protein damage and also by increasing the antioxidant status. Hence, the nanoconjugated vancomycin may be used as a potent free-radical scavenger antioxidative product and as well as a potential therapeutic agent against staphylococcal infection. 


\section{Abbreviations}

$\begin{array}{ll}\text { CAT: } & \text { Catalase } \\ \text { CFU: } & \text { Colony formation unit } \\ \text { CMC: } & \text { Carboxymethyl chitosan } \\ \text { CMC-EDBE-FA: Carboxymethyl } & \text { chitosan-2,2' ethylenedioxy bis } \\ & \text { ethylamine-Folate } \\ \text { CS: } & \text { Chitosan } \\ \text { DTNB: } & 5^{\prime}, 5^{\prime} \text {-dithio(bis)-2-nitrobenzoic acid } \\ \text { EDBE: } & \text { 2, 2' ethylenedioxy bis-ethylamine } \\ \text { EDTA: } & \text { Ethylene diamine tetra acetate } \\ \text { GPx: } & \text { Glutathione peroxidase } \\ \text { GR: } & \text { Glutathione reductase } \\ \text { GSH: } & \text { Reduced glutathione } \\ \text { GSSG: } & \text { Oxidized glutathione } \\ \text { GST: } & \text { Glutathione-s-transferase } \\ \text { ip: } & \text { Intraperitoneal } \\ \text { H }{ }_{2}: & \text { Hydrogen peroxide } \\ \text { iNOS: } & \text { Inducible nitric oxide synthase } \\ \text { MDA: } & \text { Malondialdehyde } \\ \text { NO: } & \text { Nitric oxide } \\ \text { PBS: } & \text { Phosphate buffer saline } \\ \text { PMN: } & \text { Polymorphonuclear neutrophils } \\ \text { ROS: } & \text { Reactive oxygen species } \\ \text { rpm: } & \text { Rotation per minute } \\ \text { S. aureus: } & \text { Staphylococcus aureus } \\ \text { SDS: } & \text { Sodium dodecyl sulfate } \\ \text { SOD: } & \text { Superoxide dismutase } \\ \text { SSA: } & \text { Sulfosalicylic acid } \\ \text { TBARS: } & \text { Thiobutiric acid reactive substance } \\ \text { TCA: } & \text { Vaureus. } \\ \text { VRSA: } & \\ & \end{array}$

\section{Conflict of Interests}

The authors declare that there is no conflict of interests.

\section{Acknowledgments}

The authors express gratefulness to the Department of Biotechnology, Government of India for funding. The authors also express gratefulness to Vidyasagar University, Midnapore and Indian Institute of Technology, Kharagpur for providing the facilities to execute these studies.

\section{References}

[1] T. L. Bannerman, "Staphylococcus, Micrococcus, and other catalasepositive cocci that grow aerobically," in Manual of Clinical Microbiology, P. R. Murray, E. J. Baron, J. H. Jorgensen, M. A. Pfaller, and R. H. Yolken, Eds., vol. 8, pp. 384-404, ASM Press, Washington, DC, USA, 2003.

[2] A. Giacometti, O. Cirioni, A. M. Schimizzi et al., "Epidemiology and microbiology of surgical wound infections," Journal of Clinical Microbiology, vol. 38, no. 2, pp. 918-922, 2000.

[3] W. H. Swanston, "Methicillin resistant Staphylococcus aureus," West Indian Medical Journal, vol. 48, no. 1, pp. 20-22, 1999.
[4] M. Mcdonald, "The epidemiology of methicillin-resistant Staphylococcus aureus: surgical relevance 20 years on," Australian and New Zealand Journal of Surgery, vol. 67, no. 10, pp. 682-685, 1997.

[5] G. Kac, A. Buu-Hoï, E. Herisson, P. Biancardini, and C. Debure, "Methicillin-resistant Staphylococcus aureus nosocomial acquisition and carrier state in a wound care center," Archives of Dermatology, vol. 136, no. 6, pp. 735-739, 2000.

[6] W. R. Jarvis, "Infection control and changing health-care delivery systems," Emerging Infectious Diseases, vol. 7, no. 2, pp. 170-173, 2001.

[7] K. M. D. Coltman, "Urinary tract infections. New thoughts on an old subject," Practitioner, vol. 223, no. 1335, pp. 351-355, 1979.

[8] K. W. Bayles, C. A. Wesson, L. E. Liou, L. K. Fox, G. A. Bohach, and W. R. Trumble, "Intracellular Staphylococcus aureus escapes the endosome and induces apoptosis in epithelial cells," Infection and Immunity, vol. 66, no. 1, pp. 336-342, 1998.

[9] B. C. Kahl, M. Goulian, W. Van Wamel et al., "Staphylococcus aureus RN6390 replicates and induces apoptosis in a pulmonary epithelial cell line," Infection and Immunity, vol. 68, no. 9, pp. 5385-5392, 2000.

[10] C. A. Wesson, J. Deringer, L. E. Liou, K. W. Bayles, G. A. Bohach, and W. R. Trumble, "Apoptosis induced by Staphylococcus aureus in epithelial cells utilizes a mechanism involving caspases 8 and 3," Infection and Immunity, vol. 68, no. 5, pp. 2998-3001, 2000.

[11] I. Nuzzo, M. R. Sanges, A. Folgore, and C. R. Carratelli, "Apoptosis of human keratinocytes after bacterial invasion," FEMS Immunology and Medical Microbiology, vol. 27, no. 3, pp. 235-240, 2000.

[12] B. E. Menzies and I. Kourteva, "Staphylococcus aureus $\alpha$-toxin induces apoptosis in endothelial cells," FEMS Immunology and Medical Microbiology, vol. 29, no. 1, pp. 39-45, 2000.

[13] C. A. Wesson, L. E. Liou, K. M. Todd, G. A. Bohach, W. R. Trumble, and K. W. Bayles, "Staphylococcus aureus Agr and Sar global regulators influence internalization and induction of apoptosis," Infection and Immunity, vol. 66, no. 11, pp. 52385243, 1998.

[14] K. A. Tucker, S. S. Reilly, C. S. Leslie, and M. C. Hudson, "Intracellular Staphylococcus aureus induces apoptosis in mouse osteoblasts," FEMS Microbiology Letters, vol. 186, no. 2, pp. 151-156, 2000.

[15] W. M. M. Kirby, "Extraction of a highly potent penicillin inactivator from penicillin resistant staphylococci," Science, vol. 99, no. 2579 , pp. $452-453,1944$.

[16] W. C. Hellinger, "Confronting the problem of increasing antibiotic resistance," Southern Medical Journal, vol. 93, no. 9, pp. 842-848, 2000.

[17] V. M. D’Costa, K. M. McGrann, D. W. Hughes, and G. D. Wright, "Sampling the antibiotic resistome," Science, vol. 311, no. 5759, pp. 374-377, 2006.

[18] R. Bax, R. Bywater, G. Cornaglia et al., "Surveillance of antimicrobial resistance-what, how and whither?" Clinical Microbiology and Infection, vol. 7, no. 6, pp. 316-325, 2001.

[19] D. M. Livermore, "The need for new antibiotics," Clinical Microbiology and Infection, vol. 10, no. 4, supplement, pp. 1-9, 2004.

[20] H. C. Neu, "The crisis in antibiotic resistance," Science, vol. 257, no. 5073, pp. 1064-1073, 1992.

[21] E. Khor and L. Y. Lim, "Implantable applications of chitin and chitosan," Biomaterials, vol. 24, no. 13, pp. 2339-2349, 2003. 
[22] M. Dornish, D. Kaplan, and Ø. Skaugrud, "Standards and guidelines for biopolymers in tissue-engineered medical products: ASTM alginate and chitosan standard guides," Annals of the New York Academy of Sciences, vol. 944, pp. 388-397, 2001.

[23] K. A. Athanasiou, A. R. Shah, R. J. Hernandez, and R. G. LeBaron, "Basic science of articular cartilage repair," Clinics in Sports Medicine, vol. 20, no. 2, pp. 223-247, 2001.

[24] S. V. Madihally and H. W. T. Matthew, "Porous chitosan scaffolds for tissue engineering," Biomaterials, vol. 20, no. 12, pp. 1133-1142, 1999.

[25] X. F. Liu, Y. L. Guan, D. Z. Yang, Z. Li, and K. D. Yao, "Antibacterial action of chitosan and carboxymethylated chitosan," Journal of Applied Polymer Science, vol. 79, no. 7, pp. 1324-1335, 2001.

[26] S. P. Chakraborty, S. K. Sahu, S. K. Mahapatra et al., "Nanoconjugated vancomycin: new opportunities for the development of anti-VRSA agents," Nanotechnology, vol. 21, no. 10, Article ID 105103, 2010.

[27] S. P. Chakraborty, S. K. Mahapatra, S. K. Sahu, P. Pramanik, and S. Roy, "Antioxidative effect of folate-modified chitosan nanoparticles," Asian Pacific Journal of Tropical Biomedicine, vol. 1, no. 1, pp. 29-38, 2011.

[28] S. P. Chakraborty, S. K. Mahapatra, S. K. Sahu, S. Chattopadhyay, P. Pramanik, and S. Roy, "Nitric oxide mediated Staphylococcus aureus pathogenesis and protective role of nanoconjugated vancomycin," Asian Pacific Journal of Tropical Biomedicine, vol. 1, no. 2, pp. 102-109, 2011.

[29] S. P. Chakraborty, S. Kar Mahapatra, S. K. Sahu et al., "Internalization of Staphylococcus aureus in lymphocytes induces oxidative stress and DNA fragmentation: possible ameliorative role of nanoconjugated vancomycin," Oxidative Medicine and Cellular Longevity, vol. 2011, Article ID 942123, 15 pages, 2011.

[30] S. P. Chakraborty, S. KarMahapatra, M. Bal, and S. Roy, "Isolation and identification of Vancomycin Resistant Staphylococcus aureus from post operative pus sample," Al Ameen Journal of Medical Sciences, vol. 4, no. 2, pp. 152-168, 2011.

[31] D. G. Hattie, H. L. Jon, E. C. Tony, S. W. Bridget, L. C. Ambrose, and P. L. Frederik, "Survival of Staphylococcus aureus inside neutrophils contributes to infection," Journal of Immunology, vol. 164, no. 7, pp. 3713-3722, 2000.

[32] K. Chandran and P. M. Venugopal, "Modulatory effects of curcumin on lipid peroxidation and antioxidant status during nicotine-induced toxicity," Polish Journal of Pharmacology, vol. 56, no. 5, pp. 581-586, 2004.

[33] S. K. Sandhu and G. Kaur, "Alterations in oxidative stress scavenger system in aging rat brain and lymphocytes," Biogerontology, vol. 3, no. 3, pp. 161-173, 2002.

[34] S. Sanai, M. Tomisato, N. Shinsuka, Y. Mayoko, H. Mayoko, and N. Akio, "Protective role of nitric oxide in S. aurues infection in mice," Infection and Immunity, vol. 66, pp. 1017-1028, 1998.

[35] H. Ohkawa, N. Ohishi, and K. Yagi, "Assay for lipid peroxides in animal tissues by thiobarbituric acid reaction," Analytical Biochemistry, vol. 95, no. 2, pp. 351-358, 1979.

[36] R. L. Levine, J. A. Williams, E. R. Stadtman, and E. Shacter, "Carbonyl assays for determination of oxidatively modified proteins," Methods in Enzymology, vol. 233, pp. 346-357, 1994.

[37] M. S. Moron, J. W. Depierre, and B. Mannervik, "Levels of glutathione, glutathione reductase and glutathione S-transferase activities in rat lung and liver," Biochimica et Biophysica Acta, vol. 582, no. 1, pp. 67-78, 1979.
[38] O. W. Griffith, "Determination of glutathione and glutathione sulfide using glutathione reductase and 2-Vinyl pyridine," Analytical Biochemistry, vol. 106, pp. 207-212, 1980.

[39] R. F. Mestro Del and W. McDonald, "Oxidative enzymes in tissue homogenates," in CRC Handbook of Methods for Oxygen Radical Research, R. A. Greenwald, Ed., pp. 291-296, CRC Press, Boca Raton, Fla, USA, 1986.

[40] H. Luck, "Catalase," in Methods of Enzymatic Analysis, H. W. Bergmeyer, Ed., section 3, pp. 885-894, Academic Press, New York, NY, USA, 1963.

[41] D. E. Paglia and W. N. Valentine, "Studies on the quantitative and qualitative characterization of erythrocyte glutathione peroxidase," The Journal of Laboratory and Clinical Medicine, vol. 70, no. 1, pp. 158-169, 1967.

[42] S. Miwa, "Hematology," Modern Medical Techonology, vol. 3, pp. 306-310, 1972.

[43] W. H. Habig, M. J. Pabst, and W. B. Jakoby, "Glutathione $\mathrm{S}$ transferases. The first enzymatic step in mercapturic acid formation," Journal of Biological Chemistry, vol. 249, no. 22, pp. 7130-7139, 1974.

[44] O. H. Lowry, N. J. Rosenbrough, A. L. Farr, and R. J. Randall, "Protein measurement with the Folin phenol reagent," The Journal of biological chemistry, vol. 193, no. 1, pp. 265-275, 1951.

[45] S. Kar Mahapatra, S. P. Chakraborty, S. Majumdar, B. G. Bag, and S. Roy, "Eugenol protects nicotine-induced superoxide mediated oxidative damage in murine peritoneal macrophages in vitro," European Journal of Pharmacology, vol. 623, no. 1-3, pp. 132-140, 2009.

[46] P. Y. L. Nikki and C. Y. Cheng, "Nitric oxide and cyclic nucleotides: their roles in junction dynamics and spermatogenesis," Oxidative Medicine and Cellular Longevity, vol. 1, no. 1, pp. 25-32, 2008.

[47] W. Li, R. Tsubouchi, S. Qiao, M. Haneda, K. Murakami, and M. Yoshino, "Inhibitory action of eugenol compounds on the production of nitric oxide in RAW264.7 macrophages," Biomedical Research, vol. 27, no. 2, pp. 69-74, 2006.

[48] M. Bagchi, D. Bagchi, E. Adickes, and S. J. Stohs, "Chronic effects of smokeless tobacco extract on rat liver histopathology and protection of HSP-90," Journal of Environmental Pathology, Toxicology and Oncology, vol. 14, no. 2, pp. 61-68, 1995.

[49] A. Z. Reznick and L. Packer, "Oxidative damage to proteins: Spectrophotometric method for carbonyl assay," Methods in Enzymology, vol. 233, pp. 357-363, 1994.

[50] I. M. S. Santos, A. Da Rocha Tomé, G. B. Saldanha, P. M. P. Ferreira, G. C.G. Militão, and R. M. De Freitas, "Oxidative stress in the hippocampus during experimental seizures can be ameliorated with the antioxidant ascorbic acid," Oxidative Medicine and Cellular Longevity, vol. 2, no. 4, pp. 214-221, 2009.

[51] H. Gerster, " $\beta$-Carotene, vitamin $\mathrm{E}$ and vitamin $\mathrm{C}$ in different stages of experimental carcinogenesis," European Journal of Clinical Nutrition, vol. 49, no. 3, pp. 155-168, 1995.

[52] S. Sarkar, P. Yadav, R. Trivedi, A. K. Bansal, and D. Bhatnagar, "Cadmium-induced lipid peroxidation and the status of the antioxidant system in rat tissues," Journal of Trace Elements in Medicine and Biology, vol. 9, no. 3, pp. 144-149, 1995.

[53] G. J. Wetscher, M. Bagchi, D. Bagchi et al., "Free radical production in nicotine treated pancreatic tissue," Free Radical Biology and Medicine, vol. 18, no. 5, pp. 877-882, 1995.

[54] L. Ashakumari and P. L. Vijayammal, "Addictive effect of alcohol and nicotine on lipid peroxidation and antioxidant defense mechanism in rats," Journal of Applied Toxicology, vol. 16, pp. 305-308, 1996. 
[55] L. H. Chen, S. Xi, and D. A. Cohen, "Liver antioxidant defenses in mice fed ethanol and the AIN-76A diet," Alcohol, vol. 12, no. 5, pp. 453-457, 1995.

[56] R. Nordmann and H. Rouach, "Free radical mechanisms and ethanol induced brain injury," in Pharmacological Effect of Ethanol on the Nervous System, R. A. Deitrich and V. G. Erwin, Eds., pp. 329-341, CRC Press, Boca Raton, Fla, USA, 1996.

[57] S. M. Somani, "Exercise, drugs and tissue specific antioxidant system," in Pharmacology in Exercise and Sports, S. M. Somani, Ed., pp. 57-95, CRC Press, Boca Raton Fla, USA, 1996.

[58] T. Hemachand, B. Gopalakrishnan, D. M. Salunke, S. M. Totey, and C. Shaha, "Sperm plasma-membrane-associated glutathione S-transferases as gamete recognition molecules," Journal of Cell Science, vol. 115, no. 10, pp. 2053-2065, 2002. 

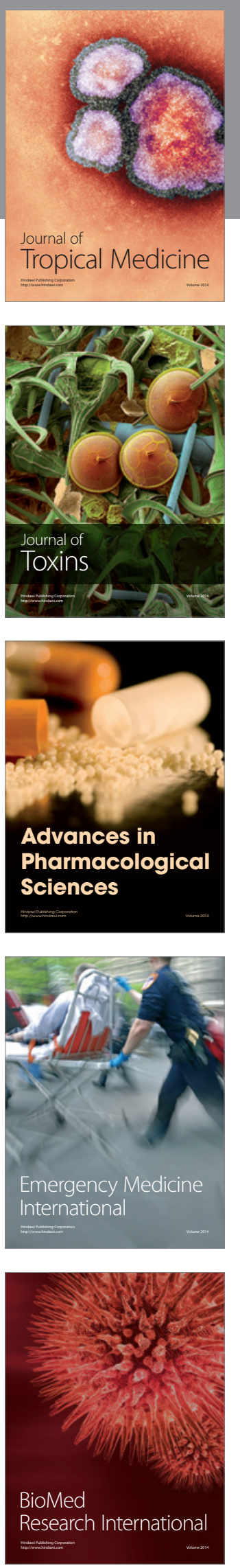
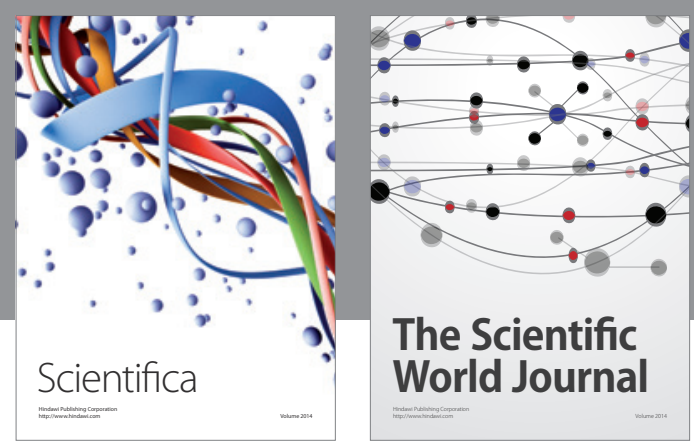

The Scientific World Journal
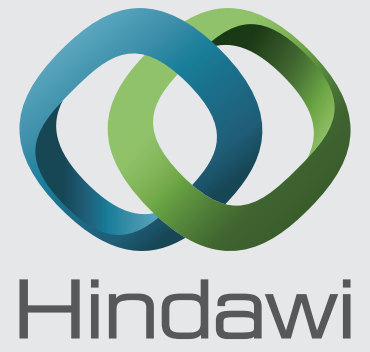

Submit your manuscripts at

http://www.hindawi.com
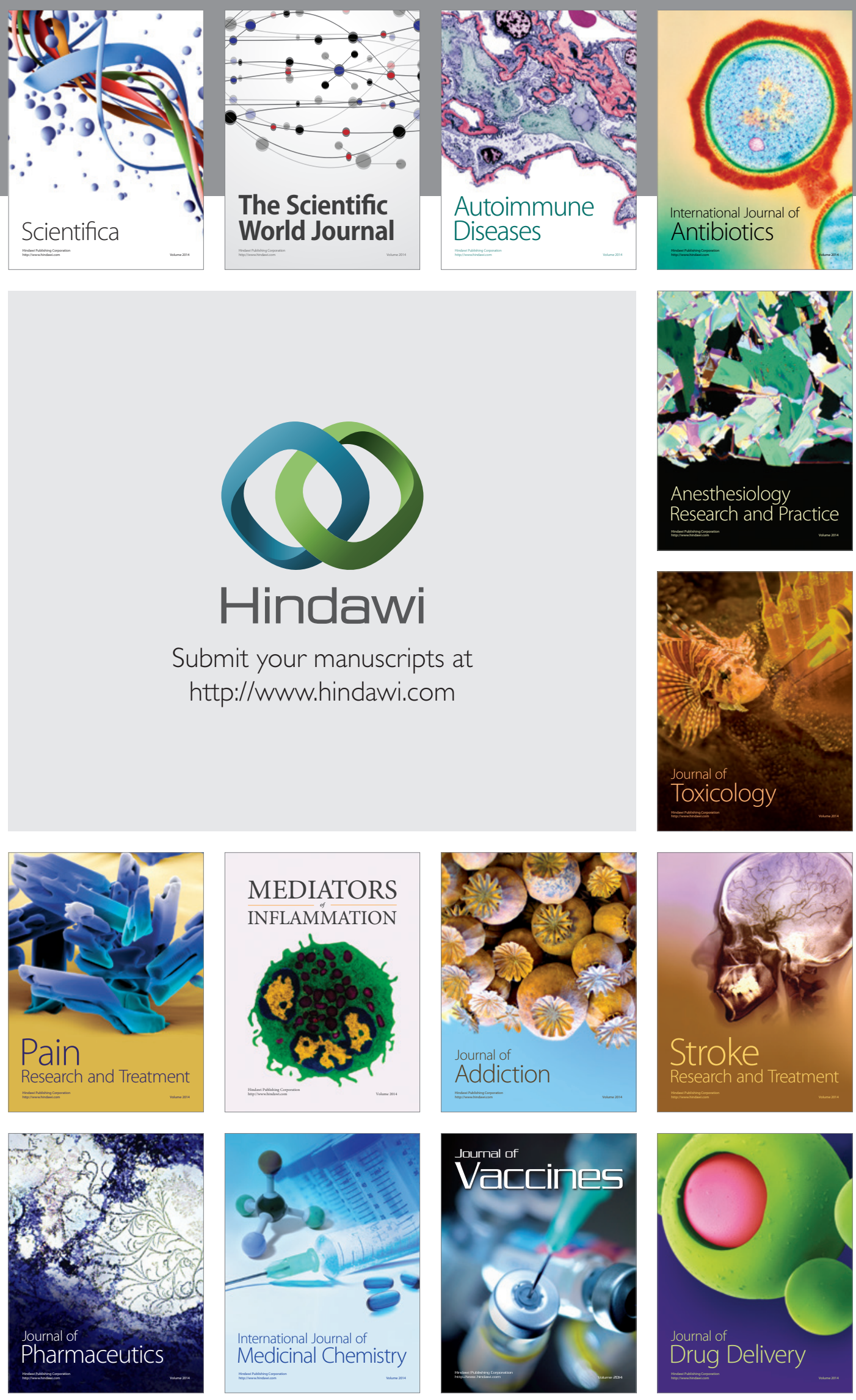